Academic Platform Journal of Engineering and Science

\title{
Farklı Mineral Katkılı Yüksek Dayanımlı Betonlarda Metagabro Agregalarının Kullanılabilirliğinin Araştırılması
}

\author{
*1 İsmail İsa Atabey, ${ }^{2}$ Serhat Çelikten, ${ }^{3}$ Ümit Yurt \\ ${ }^{1}$ Nevşsehir Hacı Bektaş Veli Üniversitesi, Müh. Mim. Fak., İnşaat Müh. Böl., ismailatabey@nevsehir.edu.tr, \\ ${ }^{2}$ Nevşsehir Hacı Bektaş Veli Üniversitesi, Müh. Mim. Fak., İnşaat Müh. Böl., serhatcelikten@ nevsehir.edu.tr, \\ ${ }^{3}$ Düzce Üniversitesi, Düzce MYO, İnşaat Böl., umityurt@duzce.edu.tr,
}

Araştırma Makalesi

Geliș Tarihi: 24.03 .2020

Kabul Tarihi: 10.07.2020

$\ddot{O} \mathbf{z}$

Günümüzde yüksek dayanımlı betonlar (YDB) geniş bir kullanım alanına sahiptir. Fakat beton karışımları ile ilgili agrega türü, özelikleri, dağlımı ve mineral katkıların kullanım oranları mekanik ve fiziksel özelliklerine önemli etkileri olmaktadır. Bu çalışmada, kalker ve metagabro agregaları ayrı ayrı kullanılarak yüksek dayanımlı betonlar üretilmiş ve agrega türünün betonların özelliklerine etkileri incelenmiştir. Bu amaçla iki farklı agrega grubu, iki farklı F sınıfı uçucu kül ve silis dumanı ile 12 karışım hazırlanarak üretilen numunelere birim ağırlık, yoğunluk, su emme ve boşluk oranı, basınç dayanımı ve ultrases geçiş hızı deneyleri uygulanmıştır. Su/bağlayıcı oranı 0,40, çimento dozaj1 $400 \mathrm{~kg}$ olarak belirlenmiştir. Karışımlara \%10 oranında mineral katkılar ayrı ayrı ve ikili karışımlar şeklinde ilave edilmiştir. Kıvamı $15 \pm 2 \mathrm{~cm}$ değerinde tutabilmek için beton karışımlarına \%1 oranında hiper akışkanlaştırıcı eklenmiştir. Metagabro agregaları ile üretilen betonlarda en yüksek 28 günlük basınç dayanımı (76,7 MPa) Sugözü uçucu külü ve silis dumanının beraber kullanıldığı karışımlarda elde edilmiştir. Kalker tipi agregalar ile 81,4 MPa elde edilmiştir. Hem metagabro hem kalker tipi agrega grubu ile yüksek dayanımlı beton elde edilebilirken, kalker tipi agregalar ile üretilen betonlarda \%15'e varan oranlarda daha yüksek basınç dayanımı elde edilmiştir.

Anahtar Kelimeler: Kalker, Metagabro, Mineral katkı, Yüksek dayanımlı beton

\section{Investigation on the Use of Metagabbro Aggregates in High Strength Concretes Made with Different Mineral Additives}

\author{
*1 İsmail İsa Atabey, ${ }^{2}$ Serhat Çelikten, ${ }^{3}$ Ümit Yurt \\ ${ }^{1}$ Nevşehir Hacı Bektaş Veli Üniversitesi, Müh. Mim. Fak., İnşaat Müh. Böl., ismailatabey@nevsehir.edu.tr, \\ ${ }^{2}$ Nevşehir Hacı Bektaş Veli Üniversitesi, Müh. Mim. Fak., İnşaat Müh. Böl., serhatcelikten@nevsehir.edu.tr, \\ ${ }^{3}$ Düzce Üniversitesi, Düzce MYO, İnşaat Böl., umityurt@duzce.edu.tr,
}

\begin{abstract}
Today, high strength concretes (HSC) have a wide usage area. However, considering the type, properties and gradation of aggregates, and amount of mineral additives used in concrete mixtures have important effects on their mechanical and physical properties. In this study, high strength concretes were produced by using limestone and metagabro aggregates separately and the effects of aggregate type on the properties of concretes were investigated. For this purpose, 12 different mixtures were prepared with two different aggregate groups, two different F class fly ash and silica fume, and unit weight, density, water absorption and porosity, compressive strength and ultrasonic pulse velocity tests were applied. Water to binder ratio and cement dosage of mixtures are determined constant as 0,40 , as $400 \mathrm{~kg} / \mathrm{m}^{3}$, respectively. For the constant slump value of $15 \pm 2 \mathrm{~cm}, 1 \%$ hyperplasticizer was added to the mixtures. The highest 28 days' strength of the concretes made with metagabbro aggregates was 76.7 MPa obtained on the mixture produced with binary mixture of Sugözü fly ash and silica fume. It was obtained as 81,4 $\mathrm{MPa}$ with limestone aggregates. While high-strength concrete can be obtained with both metagabbro and limestone type aggregates, up to $15 \%$ higher compressive strength has been achieved in concretes produced with limestone-type aggregates..
\end{abstract}

Keywords: Limestone, Metagabbro, Mineral additive, High strength concrete 


\section{GÍRİ̧̧}

Dünyadaki beton tüketimi 2012 yılı itibariyle 10 milyar metreküpü aşmıştır [1]. Bu devasa tüketim her geçen gün artarak devam etmekte ve 2050 yılı itibariyle de 18 milyar tona ulaşacağı tahmin edilmektedir [2]. Artan tüketim ile beton üretiminde kullanılan hammaddelerin sürdürülebilirliği sorgulanır hale gelmiştir. Ekonomikliği ve yüksek dayanımı nedeniyle betonda en çok kullanılan malzeme olan agregalar için de tedarik sorunu meydana gelmeye başlamıştır. Bu nedenle çeşitli kayaçlardan elde edilen agregaların beton üretiminde kullanılabilirliğinin araştırılması da sürdürülebilir beton üretimi için elzemdir. $\mathrm{Bu}$ amaçla agrega türünün betonun mekanik ve durabilite özellikleri üzerine etkileri daha önce birçok araştırmacı tarafından irdelenmiştir.

Aitcin ve Mehta [3] benzer karışım oranları ile diyabaz, kireçtaşı, granit ve dere agregalarını ayrı ayrı kullanarak betonlar üretmişlerdir. Araştırmacılar diyabaz ve kireçtaşı agregaları ile ürettikleri betonların basınç dayanımlarının granit ve dere agregaları ile ürettikleri betonlara göre daha yüksek olduğunu rapor etmişlerdir. Bishr ve ark. [4] yüksek dayanımlı betonların basınç ve yarmada çekme dayanımları üzerine iri agrega türünün etkilerini araştırmışlardır. Deney sonuçları demir-çelik cürufu agregası ile üretilen betonların kireçtaşı ile üretilenlere göre daha yüksek basınç ve yarmada çekme dayanımına sahip olduğunu göstermiştir. Ezeldin ve Aitcin [5] dört farklı iri agrega ile normal ve yüksek dayanımlı betonlar üretmişler ve ürettikleri betonların eğilme ve basınç dayanımlarının agrega türüne göre değişimini araştırmışlarıdır. Araştırmacılar, ürettikleri normal dayanımlı betonların dayanımlarında agrega türüne göre önemli bir değişim gözlememişlerdir. Ancak, kireçtaşı ile üretilen yüksek dayanımlı betonların çakıl veya granit ile üretilenlere göre daha yüksek basınç dayanımına sahip olduğunu belirtmişlerdir. Kılıç ve ark. [6] bazalt, gabbro, kuvarzit, kireçtaşı ve kumtaşı agregaları ile ayrı ayrı ürettikleri yüksek dayanımlı betonların dayanım ve aşınma özelliklerine agrega türünün etkisini araştırmışlardır. Araştırmacılar basınç dayanımlarının yüksekten düşüğe sırasıyla bazalt, gabbro, kireçtaşı, kuvarzit ve kumtaşı kullanılan betonlarda elde edildiğini rapor etmişlerdir. En yüksek eğilme dayanımı ise gabro ile üretilen betonlarda gözlemişlerdir. Araştırmacılar, gabro ve bazalt agregası ile üretilen betonların aşınma direncinin diğer betonlara kıyasla daha yüksek olduğunu ve kum taşı ile üretilen betonların diğer betonlarda göre daha düşük aşınma direncine sahip olduğunu belirtmişlerdir. Diğer taraftan bir tür entrüsiv volkanik kayaç olan metagabronun da beton üretiminde kullanılabilirliğinin araştırılması da sürdürülebilir üretim, yerel kaynakların değerlendirilmesi ve performans değerlemesi açısından önem arz etmektedir. Ancak, metagabro kayaçlarının betonda agrega olarak kullanılabilirliğine dair halen yeterli sayıda çalışma yapılmamıştır. Çimento üretimi 2010 yılı verilerine göre küresel $\mathrm{CO}_{2}$ salınımının yaklaşık \%7 sinden sorumludur [7]. $\mathrm{Bu}$ devasa salınım bilim insanlarının çimento içeriği daha az beton üretilebilirliğini araştırmaya sevk etmiştir [8].
Geleneksel betona göre daha çevreci, ekonomik ve yüksek performanslı beton üretmenin bir yolu da çimento yerine çimento ile birlikte çeşitli puzolanların kullanılmasıdır. Bu amaçla, uçucu kül $[9,10]$ silis dumanı $[11,12]$, yüksek firın cürufu $[13,14]$, pirinç kabuğu külü $[15,16]$ ve metakaolin $[17,18]$ gibi birçok doğal ve yapay puzolanın normal ve yüksek dayanımlı betonda kullanılabilirliği ve beton özelliklerine etkileri araştırılmış ve araştırılmaya halen devam etmektedir. Bununla birlikte, çimento yerine kullanılan puzolanın kimyasal ve fiziksel karakteristiği betonun özelliklerini önemli derecede etkilemektedir. $\mathrm{Bu}$ nedenle de, özellikle endüstriyel atıklarla üretilen betonların özellikleri farklılık göstermektedir. Bu çalışmada, betonda yaygın olarak kullanılan kalker agregası ile betonda kullanımı noktasında daha az araştırılan metagabro agregaları ayrı ayrı kullanılarak yüksek dayanımlı betonlar üretilmiş ve agrega türünün üretilen betonların özelliklerine etkileri irdelenmiştir. Ayrıca Çatalağzı (Zonguldak) ve Sugözü (Adana) Termik Santrallerinden alınan iki farklı uçucu kül ve Antalya Eti Elektrometalurjı tesisi atığı olan silis dumanının yüksek dayanımlı betonların birim ağırlık, yoğunluk, ultrases geçiş hızı, basınç dayanımı, su emme ve boşluk oranına etkileri araştırılmıştır.

\section{MALZEME VE YÖNTEM}

\subsection{Cimento ve Mineral Katkılar}

Çalışmada TS EN 197-1'e [19] uygun CEM I 42,5R tipi çimento (PÇ) kullanılmıştır. Mineral katkı olarak ASTM C618 [20] standardına göre iki farklı F sınıfı uçucu kül kullanılmıştır. Adana ili Yumurtalık ilçesi Sugözü köyünde bulunan Sugözü Termik Santrali Uçucu Külü (SG UK) ve Zonguldak ili Çatalağzı beldesinde bulunan Çatalağzı Termik Santrali Uçucu Külü (ÇA UK) temin edilmiştir. Silis dumanı (SD) Antalya Ferrokrom tesislerinden elde edilmiştir. Çimento ve mineral katkılara ait kimyasal ve fiziksel özellikler Tablo 1'de verilmiştir

Tablo 1. Çimento ve mineral katkıların kimyasal ve fiziksel özellikleri

\begin{tabular}{|c|c|c|c|c|}
\hline Özellik & $\mathbf{P C ̧}$ & SG UK & ÇA UK & SD \\
\hline $\mathrm{SiO}_{2}(\%)$ & 18,80 & 60,51 & 54,68 & 93,10 \\
\hline $\mathrm{Al}_{2} \mathrm{O}_{3}(\%)$ & 5,81 & 21,69 & 25,94 & 0,55 \\
\hline $\mathrm{Fe}_{2} \mathrm{O}_{3}(\%)$ & 2,61 & 7,85 & 6,81 & 1,35 \\
\hline $\mathrm{CaO}(\%)$ & 62,90 & 1,52 & 3,12 & 0,49 \\
\hline $\operatorname{MgO}(\%)$ & 1,29 & 1,65 & 1,55 & 0,36 \\
\hline $\mathrm{SO}_{3}(\%)$ & 2,74 & 0,53 & 0,34 & 0,1 \\
\hline $\mathrm{Na}_{2} \mathrm{O}(\%)$ & \multirow{2}{*}{0,74} & 0,92 & 0,39 & 0,29 \\
\hline $\mathrm{K}_{2} \mathrm{O}(\%)$ & & - & - & 0,91 \\
\hline Ser. CaO (\%) & 0,70 & 0,18 & 0,02 & - \\
\hline $\mathrm{Cl}^{-}(\%)$ & 0,033 & 0,010 & 0,004 & - \\
\hline K. K. (\%) & 3,27 & 2,42 & 3,30 & 2,85 \\
\hline >45 Mik. (\%) & - & 18,47 & 29,0 & - \\
\hline Yoğ. $\left(\mathrm{g} / \mathrm{cm}^{3}\right)$ & 3,15 & 2,29 & 2,13 & 2,31 \\
\hline
\end{tabular}




\subsection{Agrega}

Beton karışımlarında maksimum tane boyutu 22,4 mm olan iki farklı metagabro (Şekil 1) ve kalker agregası (Şekil 2) ayrı ayrı kullanılmıştır. Agregalara ait değerler Tablo 2'de verilmiştir.

Tablo 2. Agrega tane dağılım grupları ve özgül ağırlıkları

\begin{tabular}{cccc}
\hline \multirow{2}{*}{ Agregalar } & Özellik & $\begin{array}{c}\text { Gradasyon } \\
\text { Yüzdeleri }\end{array}$ & $\begin{array}{c}\text { Özgül } \\
\text { Ăgırlık }\end{array}$ \\
\hline \multirow{3}{*}{ Metagabro } & $0-5 \mathrm{~mm}$ & $\% 45$ & 2,69 \\
\cline { 2 - 4 } & $5-12 \mathrm{~mm}$ & $\% 34$ & 2,78 \\
\cline { 2 - 4 } Kalker & $12-22.4 \mathrm{~mm}$ & $\% 21$ & 2,79 \\
\cline { 2 - 4 } & $0-5 \mathrm{~mm}$ & $\% 45$ & 2,74 \\
\cline { 2 - 4 } & $5-12 \mathrm{~mm}$ & $\% 34$ & 2.72 \\
\hline \multirow{3}{*}{ 12-22.4 mm } & $\% 21$ & 2,71 \\
\hline
\end{tabular}

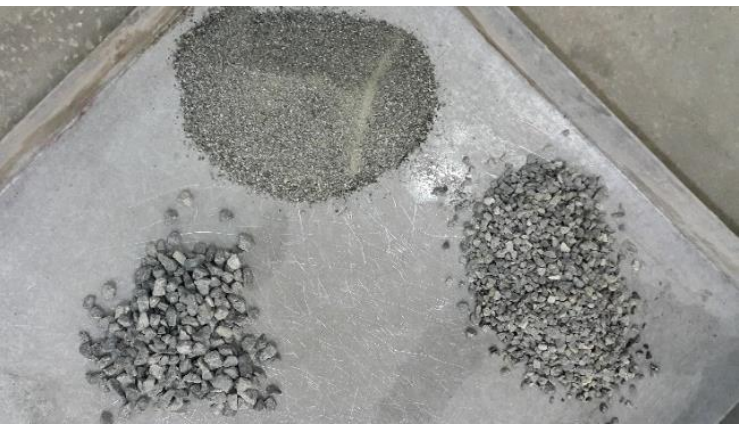

Şekil 1. Metagabro agregası

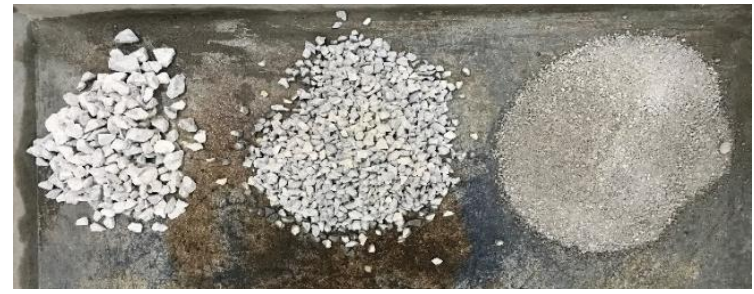

Şekil 2. Kalker agregası

\subsection{Hiper Akışkanlaştırıcı ve Su}

Beton üretiminde karıșım suyunu yüksek oranda azaltan TS EN 934-2+A1 [21] standardına uygun hiper akışkanlaştırıcı beton katkısı Polydos EG 450 kullanılmıştır. Katkı özellikleri Tablo 3'de verilmiştir. Karışım hazırlamada TS EN 1008'e [22] göre içilebilir musluk suyu kullanılmıştır.
Tablo 3. Hiper akışkanlaştırıcı katkının özellikleri

\begin{tabular}{ll}
\hline Kimyasal Özelliği & Polikarboksilat Esaslı \\
\hline Renk-Görünüm & Kahverengi Sıv1 \\
\hline Yoğunluk & $1,05 \pm 0,02 \mathrm{~kg} / 1$ \\
\hline Alkali İçeriği (TS EN 480-12) & $<\% 4$ \\
\hline Klor İçeriği ( TS EN 480-10) & $<\% 0,1$ \\
\hline
\end{tabular}

\subsection{Yöntem}

Bu çalışmada, bağlayıcı çimento dozajı birim metreküp için 400 kg'dır. Su/bağlayıcı oranı 0,40'tır. Deneysel çalışmalarda hazırlanan karışımların çökme değerleri $15 \pm 2$ $\mathrm{cm}$ olacak şekilde çimento ağırlığının \%1 oranında hiper akışkanlaştırıcı katkı maddesi kullanılmıştır. Beton karışımlarında mineral katkı olarak Sugözü Uçucu Külü, Çatalağzı Uçucu Külü ve Silis Dumanı toplam çimento oranının \%10’u kadar kullanılmıştır. İki farklı (metagabro M ve kalker tipi K) agrega için hacimce eş değer oranlarda üç grup agrega ile karışım hazırlanarak $100 \times 100 \times 100 \mathrm{~mm}$ numuneler üretilmiștir (Șekil 3 ve Şekil 4). 0-5 mm agregalar $\% 45,5-12 \mathrm{~mm}$ agregalar \%34 ve 12-22,4 $\mathrm{mm}$ agregalar \%21 oranında alınarak $1 \mathrm{~m}^{3}$ beton için karışım miktarları Tablo 4 'te verilmiştir. Laboratuvar çalışması sonucu üretilen 12 grup beton numunelerine 28 gün sonunda birim ağırlık ve yoğunluk, su emme ve boşluk oranı, basınç dayanımı ve ultrases geçiş hızı deneyi uygulanmıştır.

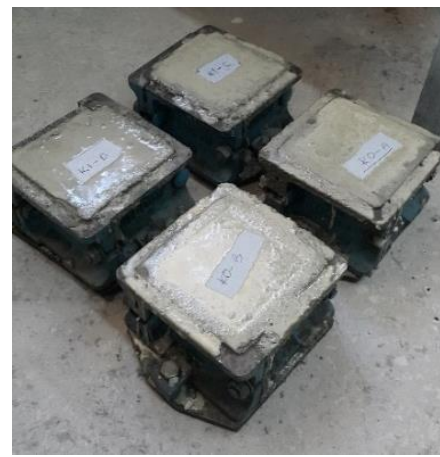

Şekil 3. Metagabro agregası ile hazırlanan numuneler

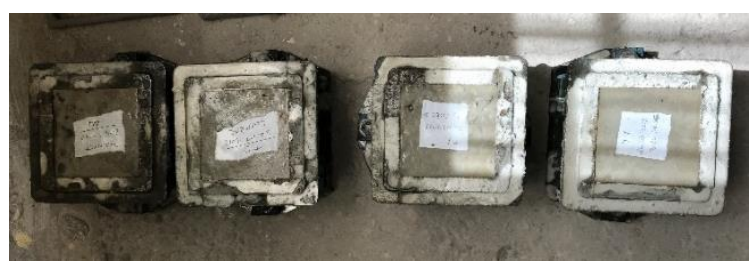

Şekil 4. Kalker agregası ile hazırlanan numuneler 
Tablo 4. $1 \mathrm{~m}^{3}$ karışıma giren malzeme miktarları

\begin{tabular}{|c|c|c|c|c|c|c|c|c|c|c|c|}
\hline 可 & 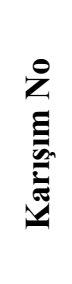 & 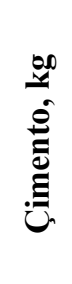 & 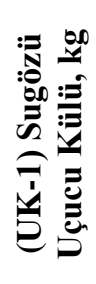 & 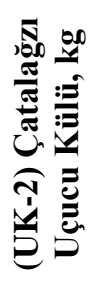 & 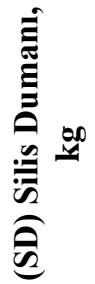 & 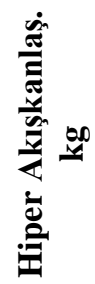 & $\stackrel{\sim}{\sim}$ & 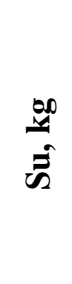 & 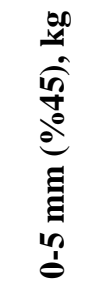 & 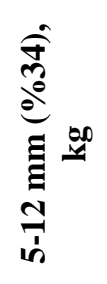 & 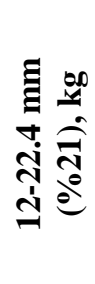 \\
\hline \multirow{6}{*}{ 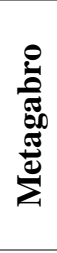 } & M0 & 400 & - & - & - & 4 & 0,40 & 160 & 862,4 & 651,6 & 402,4 \\
\hline & M1 & 400 & 40 & - & - & 4 & 0,40 & 160 & 840,8 & 635,3 & 392,4 \\
\hline & M2 & 400 & - & - & 40 & 4 & 0,40 & 160 & 839,9 & 634,6 & 392,0 \\
\hline & M3 & 400 & 20 & - & 20 & 4 & 0,40 & 160 & 840,4 & 635,0 & 392,2 \\
\hline & M4 & 400 & - & 40 & - & 4 & 0,40 & 160 & 839,2 & 634,1 & 391,6 \\
\hline & M5 & 400 & - & 20 & 20 & 4 & 0,40 & 160 & 839,6 & 634,3 & 391,8 \\
\hline \multirow{6}{*}{ 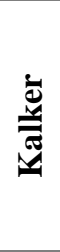 } & K0 & 400 & - & - & - & 4 & 0,40 & 160 & 858,0 & 648,3 & 400,4 \\
\hline & K1 & 400 & 40 & - & - & 4 & 0,40 & 160 & 836,5 & 632,1 & 390,4 \\
\hline & K2 & 400 & - & - & 40 & 4 & 0,40 & 160 & 835,7 & 631,4 & 390,0 \\
\hline & K3 & 400 & 20 & - & 20 & 4 & 0,40 & 160 & 836,1 & 631,7 & 390,2 \\
\hline & K4 & 400 & - & 40 & - & 4 & 0,40 & 160 & 836,5 & 632,1 & 390,4 \\
\hline & K5 & 400 & - & 20 & 20 & 4 & 0,40 & 160 & 836,1 & 631,7 & 390,2 \\
\hline
\end{tabular}

\section{BULGULAR}

\subsection{Birim Ağırlık ve Yoğunluklar}

Çalışmada üretilen numunelerin ağırlıkları alınıp numune hacmine bölünerek birim ağırlıkları hesaplanmıștır. Ayrıca beton örneklerinin Arşimet yöntemi ile sudaki ağırlık, suya doygun ve etüv kurusu ağırlıkları tartılarak yoğunlukları belirlenmiştir. TS EN 12390-7 [23] standardına göre elde edilen sonuçlar Tablo 5 ve Tablo 6'da verilmiştir.

Tablo 5. Metagabro agregası içeren betonlara ait birim ağırlık ve yoğunluk deney sonuçları

\begin{tabular}{llllll} 
& & & \\
M0 & 2,62 & 2,57 & 2,62 & 2,50 & 2,54 \\
\hline M1 & 2,55 & 2,50 & 2,60 & 2,47 & 2,52 \\
\hline M2 & 2,60 & 2,56 & 2,59 & 2,50 & 2,54 \\
\hline M3 & 2,63 & 2,60 & 2,61 & 2,52 & 2,55 \\
\hline M5 & 2,63 & 2,59 & 2,63 & 2,52 & 2,56 \\
\hline & 2,63 & 2,60 & 2,62 & 2,54 & 2,57 \\
\hline
\end{tabular}

Tablo 6. Kalker agregası içeren betonlara ait birim ağırlık ve yoğunluk deney sonuçları

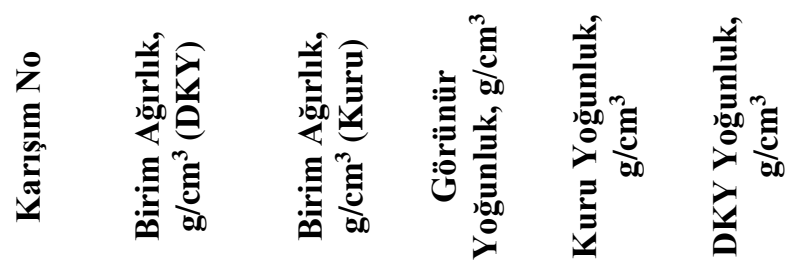

\begin{tabular}{llllll}
\hline K0 & 2,50 & 2,45 & 2,60 & 2,46 & 2,51 \\
\hline K1 & 2,52 & 2,48 & 2,57 & 2,46 & 2,50 \\
\hline K2 & 2,45 & 2,42 & 2,59 & 2,51 & 2,54 \\
\hline K3 & 2,48 & 2,44 & 2,58 & 2,48 & 2,52 \\
\hline K4 & 2,51 & 2,46 & 2,57 & 2,45 & 2,50 \\
K5 & 2,51 & 2,48 & 2,54 & 2,45 & 2,49
\end{tabular}

Metagabro tipi agrega kullanılarak üretilen YDB'ların DKY birim ağırlıkları 2,55-2,63 g/ $\mathrm{cm}^{3}$, kuru birim ağırlıklar 2,50$2,60 \mathrm{~g} / \mathrm{cm}^{3}$, görünür yoğunlukları 2,59-2,63 g/ $\mathrm{cm}^{3}$, kuru yoğunlukları 2,47-2,54 g/cm³, DKY yoğunlukları 2,52-2,57 $\mathrm{g} / \mathrm{cm}^{3}$ arasında hesap edilmiştir (Tablo 5). Kalker tipi agrega kullanılarak üretilen YDB'ların DKY birim ağırlıkları 2,45$2,52 \mathrm{~g} / \mathrm{cm}^{3}$, kuru birim ağırlıklar 2,42-2,48 g/ $\mathrm{cm}^{3}$, görünür yoğunluklar 2,54-2,60 g/ $\mathrm{cm}^{3}$, kuru yoğunlukları 2,45-2,51 $\mathrm{g} / \mathrm{cm}^{3}$, DKY yoğunlukları 2,49-2,54 $\mathrm{g} / \mathrm{cm}^{3}$ arasında hesap edilmiştir (Tablo 6). 


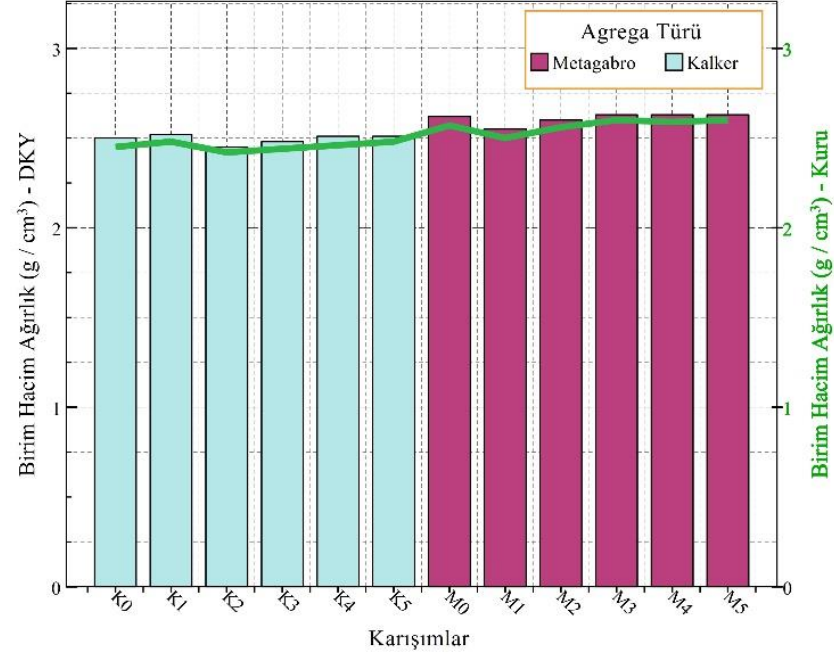

Şekil 5. Agrega türüne göre birim ağırlıkların değişimi

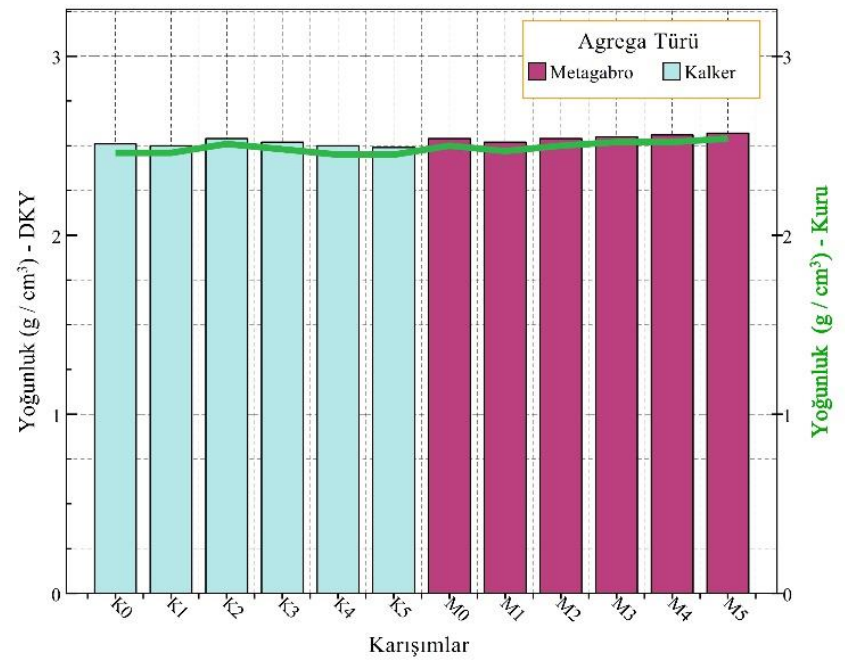

Şekil 6. Agrega türüne göre yoğunlukların değişimi

Metagabro gurubu agregaların yoğunlukları kalker agregasından fazla olduğu için genel olarak yoğunluk ve birim ağırlık değerleri metagabro agregalı yüksek dayanımlı betonlarda daha yüksektir (Şekil 5 ve Şekil 6). Her iki agrega tipi için de farklı mineral katkıların yoğunluklarının birbirine yakın olması YDB'ların birim ağırlık ve yoğunluklarında büyük farklar oluşturmamıştır. Yüksek dayanımlı beton olduğu için hiper akışkanlaştırıcı ile su oranı azaltılarak boşluklar azalmış böylece yoğunluklar ile birim ağırlıklar arasında önemli fark meydana gelmemiştir.

\subsection{Su Emme ve Boşluk Oranı}

Sertleșmiş beton numunelerinin su emme ve boşluk oranlarının belirlenmesi için 28 günlük $100 \times 100 \times 100$ mm'lik küp numuneler kullanılmıştır. Numunelerin etüv kurusu ağırlıkları ve suya doygun ağırlıkları belirlenerek Tablo 7'deki değerler elde edilmiştir.
Tablo 7. Su emme ve boşluk oranı deney sonuçları

\begin{tabular}{|c|c|c|c|c|c|}
\hline$\stackrel{1}{2}$ & 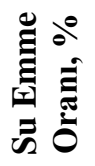 & 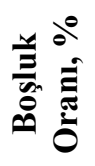 & 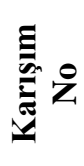 & 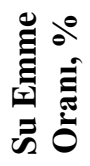 & 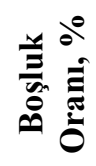 \\
\hline M0 & 1,93 & 4,81 & K0 & 2,06 & 5,09 \\
\hline M1 & 1,95 & 4,82 & K1 & 1,76 & 4,32 \\
\hline M2 & 1,39 & 3,47 & K2 & 1,43 & 3,51 \\
\hline M3 & 1,15 & 2,91 & K3 & 1,26 & 3,16 \\
\hline M4 & 1,68 & 4,23 & K4 & 1,89 & 4,63 \\
\hline M5 & 1,36 & 3,42 & K5 & 1,50 & 3,71 \\
\hline
\end{tabular}

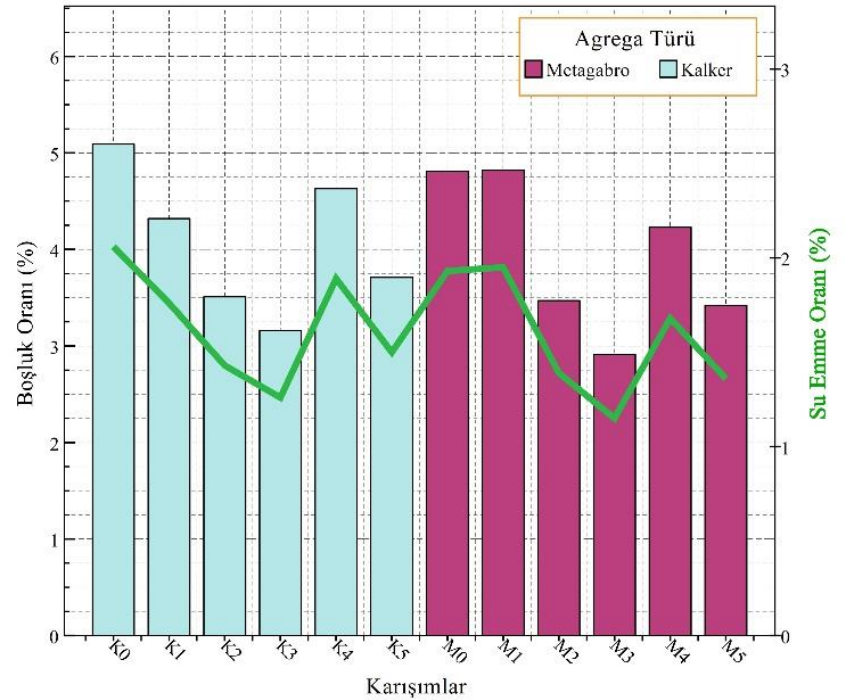

Şekil 7. Su emme -boşluk oranı değişimi

Metagabro tipi agrega ile üretilen YDB'ların su emme oranları \%1,15-1,95, boşluk oranları \%2,91-4,82 arasında elde edilmiștir. Kalker tipi agregalarla ise su emme oranları \%1,26-2,06, boşluk oranları \%3,16-5,09 arasındadır. Hem kalker hem metagabro agrega grubu ile üretilen YDB'larda mineral katkı kullanımı su emme ve boşluk oranı değerlerini düşürmüştür (Şekil 7). Sugözü uçucu külü ile üretilen betonların su emme ve boşluk oranı Çatalağzı külü ile üretilen betonlardan daha düşük değerlerdedir. Küllerin fiziksel özelikleri harçların boşluk yapısını da etkilemektedir. Her iki kül içinde silis dumanı ilavesi ile boşluk oranları dolayısıyla su emme değerleri düşmüştür. Uçucu kül tanelerinden daha ince olan silis dumanı ara boşlukları doldurarak daha sıkı bir yapı oluşturduğu öngörülmektedir. Benzer şekilde Delikurt ve Sevim [24] uçucu küllü yüksek dayanımlı beton ürettikleri çalışmalarında \%10 uçucu kül içeren karışımlarda kül içermeyen kontrol numunelerine göre daha düşük su emme ve boşluk oranı değerleri elde etmişlerdir.

\subsection{Basınç Dayanımı ve Ultrases Geçiş Hızı}

Basınç dayanımının tayini için $100 \times 100 \times 100$ mm’ lik küp numuneler üretilmiştir. Numunelerin 28 günlük basınç 
dayanımları belirlenmiştir. Numuneler, TS EN 12390-4 [25] standardına uygun olarak beton presinde basınç dayanımının tayini için deneye tabi tutulmuşlardır. TS EN 12504-4 [26] standardına göre betonun içerisine ses üstü dalgaları gönderilerek betonun bir yüzeyinden diğerine ultrases geçiş süresi hesaplanmıştır. Tahribatsız yöntem olan ultrases dalga hızı ile betonun basınç dayanımı ve boşluk oranları arasında ilişki elde edilebilmektedir (Şekil 8). Mineral katkılı farklı agregalar ile üretilen betonlara ait basınç dayanımları ve ultrases hızı deney sonuçları Tablo 8'de sunulmuştur.

Tablo 8. Basınç dayanımı ve ultrases hızı deney sonuçları

\begin{tabular}{cccccccc}
\hline $\begin{array}{c}\text { Karışım } \\
\text { No }\end{array}$ & $\begin{array}{c}\text { Ultrases } \\
\text { Hızı, m/s } \\
\text { (DKY) }\end{array}$ & $\begin{array}{c}\text { Ultrases } \\
\text { Hızı, m/s } \\
\text { (Kuru) }\end{array}$ & $\begin{array}{c}\text { Basınç } \\
\text { Dayanımı, } \\
\text { MPa }\end{array}$ & $\begin{array}{c}\text { Karışım } \\
\text { No }\end{array}$ & $\begin{array}{c}\text { Ultrases } \\
\text { Hızı, m/s } \\
\text { (DKY) }\end{array}$ & $\begin{array}{c}\text { Ultrases } \\
\text { Hızı, m/s } \\
\text { (Kuru) }\end{array}$ & $\begin{array}{c}\text { Basınç } \\
\text { Dayanımı, } \\
\text { MPa }\end{array}$ \\
\hline M0 & 5154 & 4926 & 60,1 & K0 & 5208 & 5025 & 62,5 \\
\hline M1 & 5181 & 4938 & 65,3 & K1 & 5291 & 5102 & 67,8 \\
\hline M2 & 5208 & 5051 & 70,5 & K2 & 5335 & 5163 & 80,6 \\
\hline M3 & 5263 & 5076 & 76,7 & $\mathbf{K 3}$ & 5272 & 5003 & 81,4 \\
\hline M4 & 5128 & 4820 & 59,4 & $\mathbf{K 4}$ & 5091 & 4878 & 62,3 \\
\hline M5 & 5177 & 4904 & 67,2 & $\mathbf{K 5}$ & 5226 & 4908 & 70.2 \\
\hline
\end{tabular}

Deneyler sonucunda metagabro tipi agrega ile üretilen YDB'ların DKY ultrases hizları 5128-5263 m/s, kuru ultrases hızları 4820-5076 m/s arasındadır. Kalker agregası ile DKY ultrases hızlar1 5091-5335 m/s, kuru ultrases hızları 4878-5163 m/s arasındadır. Her iki agrega grubu YDB'larda ultrases hızı değişimi kontrol karışımı ile mineral katkılı harçlardaki değişim boşluk oranlarındaki değişim ile anlamlıdır. Metagabro tipi agregalarda Sugözü uçucu külü+Silis Dumanı katkılı harçlarda boşluk oranı \%2,91 ile en düşük değerde iken DKY ultrases 5263 m/s ile en yüksek değerdedir. Benzer şekilde kalker tipi agregalarla üretilen YDB'larda boşluk oranı \%3,16 ile en düşük değerde iken DKY ultrases $5272 \mathrm{~m} / \mathrm{s}$ ile en yüksek değerdedir.

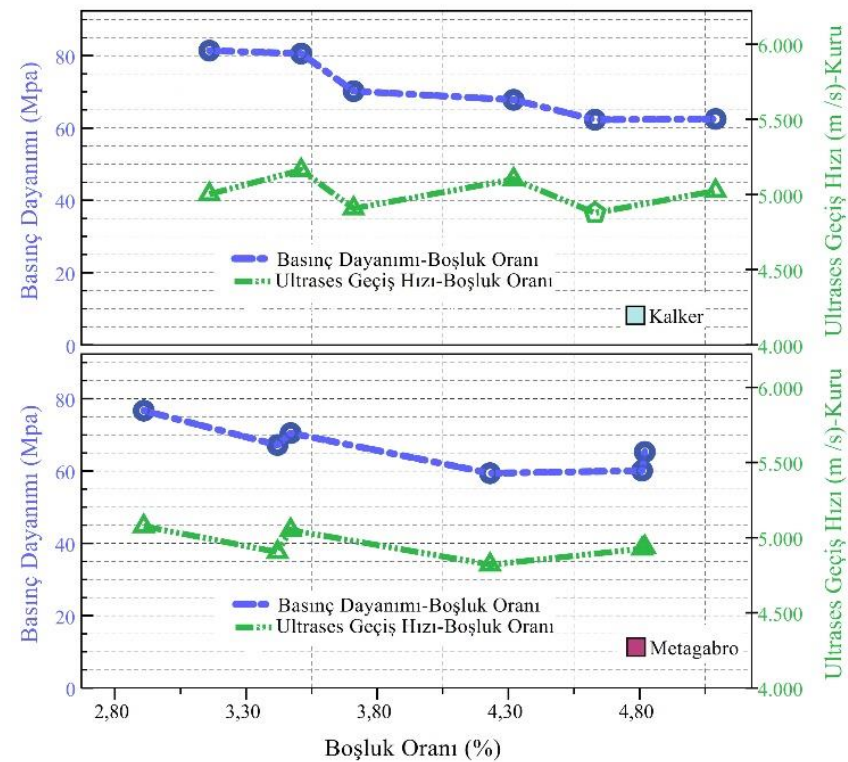

Şekil 8. Basınç dayanımı-ultrases hızlarının boşluk oranı ile değişimi
Ultrases geçiş hızı ile betonun kalitesi Feldman [27] tarafından Tablo 9'da aşağıdaki gibi ilişkilendirilmiştir. Tablo 9 incelendiğinde, bu çalışmada kireçtaşı ve metagabro agregaları ile üretilen tüm yüksek dayanımlı betonların mükemmel kalitede olduğu görülmüştür. Bununla birlikte, metagabro agregalarının yüksek kaliteye sahip beton üretiminde kullanılabileceği söylenebilir.

Tablo 9. Ultrases geçiş hızı ile beton kalitesi ilişkisi, Feldman [27]

\begin{tabular}{cc}
\hline Ultrases Geçiş Hızı, $\mathbf{m} / \mathbf{s}$ & Kalite \\
\hline$>4500$ & Mükemmel \\
\hline $3600-4500$ & İyi \\
\hline $3000-3600$ & Şüpheli \\
\hline $2100-3000$ & Zayıf \\
\hline$<2100$ & Çok Zayıf \\
\hline
\end{tabular}

Uçucu kül, silis dumanı ve uçucu kül ile birlikte silis dumanı içeriği yüksek dayanımlı betonların ultrases geçiş hızlarını artırmıştır. Bunun nedeni hem kimyasal olarak uçucu kül ve silis dumanının puzolanik reaksiyonu ile hem de özellikle silis dumanının tanecik boyutunun çimentoya göre çok küçük olması nedeniyle beton içerisindeki boşlukları doldurması ile fiziksel olarak açıklanabilir [28,29,30].

Metagabro tipi agregalarla üretilen betonların basınç dayanımlarında kontrol grubu 60,1 MPa iken mineral katkılı YDB'lar 59,4-76,7 MPa arasındadır (Şekil 9). En yüksek dayanım Sugözü uçucu külünün silis dumanı ile karışımı olan M3 karışımında 76,7 MPa olarak gerçekleşmiştir. Yoğunluğu Çatalağzı uçucu külünden daha yüksek olan Sugözü uçucu külü ile kül arasına iyi bir dolgu olan silis dumanı daha yoğun hamur kıvamı oluşturarak dayanımın gelişmesine yol açmıştır.

Kalker tipi agregalar ile YDB'larda kontrol grubu 62,5 $\mathrm{MPa}$ iken mineral katkılı YDB'lar 62,3-81,4 MPa arasındadır 
(Şekil 9). En yüksek dayanım Sugözü uçucu külü ile silis dumanı karışımında K3 karışımında 81,4 MPa olarak elde edilmiştir. Yine metagabro tipi agregalı betonlarda olduğu gibi dayanım için hamur yapısı mineral katkıların fiziksel özelliklerine bağlı olarak karışım sonucu daha iyi oluşmuştur. Genel olarak metagabro tipi agregaların yoğunluklarının kalker tipi agregalardan yüksek olmasına rağmen basınç dayanım değerlerinde oluşan düşük değerler agrega çimento hamuru ara yüzey yapısının kalker tipi agregalarda daha iyi oluşmasıdır.

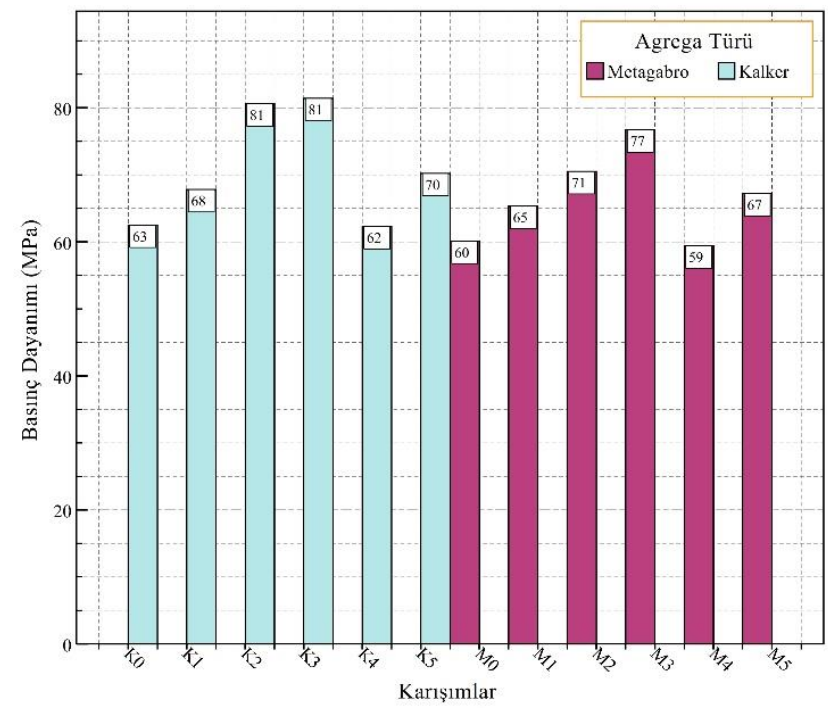

Şekil 9. Karışım gruplarına ait basınç dayanım değerleri

Benzer sonuçlar daha önce yapılan çalışmalarda da görülmüştür. Thomas ve ark. [31] çimento yerine F sinıfi uçucu kül, silis dumanı ve silis dumanı ile birlikte F sınıfı uçucu külü ayrı ayrı ikame ederek beton karışımları üretmişlerdir. Uçucu kül ile birlikte silis dumanının çimento yerine ikame edildiği betonlarda 7. günden itibaren kontrol betonlarına kıyasla daha yüksek basınç dayanımı elde edilmiştir. Ayrıca, ileri yaşlarda (90 gün ve sonrası) en yüksek basınç mukavemetine de uçucu kül ve silis dumanının beraber kullanıldığı betonlarda ulaşılmıştır. Erdem ve Kırca [32] dört farklı bağlayıcı dozajı ile yüksek dayanımlı betonlar üretmişlerdir. Araştırmacılar, çimento yerine ağırlıça \%5, 10 ve 15 oranlarında silis dumanı ikame ederek silis dumanının yüksek dayanımlı betonların basınç dayanımları üzerine etkilerini araştırmışlardır. En yüksek basınç dayanımlarına $\% 10$ ve $\% 15$ silis dumanı ile üretilen betonlarda ulaşılmıştır. Ayrıca, çalışmada silis dumanından daha düşük dayanım aktivite indeksine sahip $\mathrm{F}$ ve $\mathrm{C}$ sınıfı uçucu küller ile silis dumanı beraber kullanılarak betonlar üretilmiştir. Deney sonuçları $\% 5$ uçucu kül ile birlikte $\% 5$ silis dumanı (toplamda $\% 10$ puzolan içeriği) ile üretilen betonların 28 günlük basınç dayanımlarının $\% 10$ silis dumanı ile üretilenlere göre genellikle daha yüksek olduğunu göstermiştir. $\mathrm{Bu}$ çalışmada da uçucu kül ikame edilen betonlarda silis dumanı ikame edilen betonlara göre daha düşük dayanım elde edilmesine rağmen, bu iki puzolanın beraber kullanıldığı betonlarda sadece silis dumanı ile üretilen betonlardan daha yüksek basınç dayanımı elde edilmesi mikro yapıdaki doluluk ile açıklanabilir. Çimento, uçucu kül ve silis dumanı ile üretilen betonlardaki bağlayıcı gradasyonunun daha iyi dağılımı ile bağlayıcı olarak çimento ve silis dumanı ile üretilen betonlardan daha kompakt bir pasta elde edilmiştir. Zhao ve Sun [33] düşük su bağlayıcı oranı ile hazırlanan çimento pastalarının makro boşluklarının silis dumanı ile birlikte azaldığını ancak uçucu kül içeriği ile birlikte boşluk yapısının gelişmediğini rapor etmişlerdir. Bununla birlikte silis dumanı ve uçucu külün birlikte kullanıldığı çimento pastalarının boşluk yapılarının sadece silis dumanı ile üretilen pastalar ile benzer olduğunu belirtmişlerdir.

Yüksek dayanımlı betonlarda uçucu kül ve silis dumanı içeriği ile birlikte görülen basınç dayanımı artışının ana nedenlerinden biri bu puzolanlarda bulunan amorf yapıdaki $\mathrm{SiO}_{2}$ ile bir çimento hidratasyon ürünü olan $\mathrm{Ca}(\mathrm{OH})_{2}$ 'nin reaksiyonu sonucu ikincil C-S-H (kalsiyum silikat hidrat) jellerinin oluşmasıdır $[24,34,35]$. Bu iki puzolan içerisinde bulunan amorf $\mathrm{SiO}_{2}$ miktarı ile puzolanların farklı tanecik boyutlarına ve inceliğe sahip oluşu, yüksek dayanımlı betonlardaki dayanım artışının puzolan türüne göre farklılık göstermesine neden olmuştur.

\section{DEĞERLENDİRME VE SONUÇ}

- Kalker agregası ile üretilen kontrol karışımları metagabro ile üretilen kontrol karışımların basınç dayanımlarından \%4 daha fazladır. Puzolan içeren karışımlarda da kalker ile üretilen karışımların basınç dayanımları, metagabro ile üretilenlere göre $\% 4$ ile \%15 oranları arasında daha yüksektir.

- UK-1+SD katkılı metagabro veya kalker agregaları ile üretilen betonların basınç dayanımı kontrol karışımlarından ( $\mathrm{M} 0$ veya $\mathrm{K} 0$ ) yaklaşık \%28 daha fazladir.

- En yüksek dayanım veren M3 karışımının boşluk oranı kontrol karıșımı M0'in boşluk oranından \%40 daha düşüktür. Kalker tipi agregalı karışımlarda ise K3'ün boşluk oranı K0'dan \%39 daha düşüktür.

- $\quad \mathrm{K} 3$ grubu karışımların boşluk oranı \%3,16 iken, M3 grubu karışımların 2,91'dir. Az da olsa K3 yüksek boşluk oranına sahip olmasına rağmen M3 den yüksek dayanım vermesi agrega-çimento hamuru ara yüzey yapısı ile açıklanabilir.

- Kalker tipi agregalar ile üretilen beton karışımların (K) ultrases geçiş hızları, metagabro tipi ile üetilen karışımların (M) ultrases hızlarından daha yüksektir. Bu sonuçlar boşluk oranları ile basınç dayanımları arasındaki değişim ile uyumludur.

- Tüm karışımlarda benzer gradasyonda kullanılan metagabro agregalarının ortalama yoğunluğu 2,74 $\mathrm{g} / \mathrm{cm}^{3}$, kalker agregalarının ortalama yoğunluğu ise $2,73 \mathrm{~g} / \mathrm{cm}^{3}$ 'tür. Bu nedenle her iki grup agrega ile üretilen karışımlarda da ( $\mathrm{K}$ ve $\mathrm{M}$ )birim ağrılık ve yoğunluklar birbirine yakın değerlerdedir.

- Genel olarak hem metagabro hem kalker agregası yüksek dayanımlı beton üretimi için uygundur ancak kalker agregası ile daha yüksek dayanım elde edilebildiği için çimento maliyeti açısından da 
kalker türü agrega yüksek dayanımlı beton üretimi için metagabro agregasına göre daha uygundur.

- Ayrıca mineral katkı olarak farklı boyutlara sahip silis dumanı ve uçucu külün bir arada kullanımı daha iyi dolgu özelliği sağladığı için bu katkıların ayrı ayrı kullanımına göre daha iyi performans elde edilmesine yol açmıştır.

- Çalışmanın gelecekteki aşamalarında kapsamı genişletilerek mineral katkı oranları değişimi incelenip yüksek sıcaklık ve SEM analizi yapılarak içyapıdaki değişimin dayanım deneyleri ile bağlantısı daha net ortaya konabilir.

\section{KAYNAKÇA}

[1] Miller, S.A., Horvath, A., Monteiro, P.J.M., Readily implementable techniques can cut annual $\mathrm{CO}_{2}$ emissions from the production of concrete by over $20 \%$ ", Environ. Res. Lett., 11 (7), p. 7, 2016.

[2] Aprianti, E., "A huge number of artificial waste material can be supplementary cementitious material (SCM) for concrete production-a review part II", Journal of cleaner production, 142, 4178-4194, 2017.

[3] Aitcin P.C., Mehta P.K., "Effect of coarse aggregate characteristics on mechanical properties of high strength concrete", ACI Mater J, 87(2):103-7, 1990.

[4] Beshr H., Almusallam A.A., Maslehuddin M., "Effect of coarse aggregate quality on the mechanical properties of high strength concrete", Construction and Building Materials, 17:97-103, 2003.

[5] Ezeldin A.S, Aitcin P.C., "Effect of coarse aggregate on the behaviour of normal and high strength concretes", Cement Concrete Aggr, 13(2):121-4, 1991.

[6] Kılıç, A., Atiş, C. D., Teymen, A., Karahan, O., Özcan, F., Bilim, C., \& Özdemir, M., "The influence of aggregate type on the strength and abrasion resistance of high strength concrete", Cement and Concrete Composites, 30(4), 290296, 2008.

[7] Chen, C., Habert, G., Bouzidi, Y., \& Jullien, A., "Environmental impact of cement production: detail of the different processes and cement plant variability evaluation", Journal of Cleaner Production, 18(5), 478-485, 2010.

[8] Assi, L., Carter K., (Eddie) Deaver E., Anay R., Ziehl P., "Sustainable concrete: Building a greener future", Journal of Cleaner Production, 198: 1641-1651, 2018.

[9] Oner, A., Akyuz, S., \& Yildiz, R., “An experimental study on strength development of concrete containing fly ash and optimum usage of fly ash in concrete", Cement and Concrete Research, 35(6), 1165-1171, 2005.

[10] Shaikuthali, S. A., Mannan, M. A., Dawood, E. T., Teo, D. C. L., Ahmadi, R., \& Ismail, I., "Workability and compressive strength properties of normal weight concrete using high dosage of fly ash as cement replacement", Journal of Building Pathology and Rehabilitation, 4(1), 26, 2019.

[11] Toutanji, H., Delatte, N., Aggoun, S., Duval, R., \& Danson, A., "Effect of supplementary cementitious materials on the compressive strength and durability of short-term cured concrete", Cement and Concrete Research, 34(2), 311319, 2004.
[12] Khan, M., Rehman, A., \& Ali, M., "Efficiency of silicafume content in plain and natural fiber reinforced concrete for concrete road", Construction and Building Materials, 244, 118382, 2020

[13] Elahi, A., Basheer, P. A. M., Nanukuttan, S. V., \& Khan, Q. U. Z., "Mechanical and durability properties of high performance concretes containing supplementary cementitious materials", Construction and Building Materials, 24(3), 292-299, 2010.

[14] Wang, Y., \& Suraneni, P., "Experimental methods to determine the feasibility of steel slags as supplementary cementitious materials", Construction and Building Materials, 204, 458-467, 2019.

[15] Chouksey, A., Dev, N., \& Kumari, S., "Review Paper on Utilization Potential of Rice Husk Ash as Supplementary Cementitious Material. In Sustainable", Construction and Building Materials (pp. 673-684). Springer, Singapore, 2019.

[16] Msinjili, N. S., Schmidt, W., Rogge, A., \& Kühne, H. C., "Rice husk ash as a sustainable supplementary cementitious material for improved concrete properties", African Journal of Science, Technology, Innovation and Development, 11(4), 417-425, 2019.

[17] Badogiannis, E., Kakali, G., \& Tsivilis, S., "Metakaolin as supplementary cementitious material", Journal of Thermal Analysis and Calorimetry, 81(2), 457-462, 2005.

[18] Saridemir, M., Severcan, M. H., Ciflikli, M., Celikten, S., Ozcan, F., \& Atis, C. D., "The influence of elevated temperature on strength and microstructure of high strength concrete containing ground pumice and metakaolin", Construction and Building Materials, 124, 244-257, 2016.

[19] TS EN 197-1. , Çimento-Bölüm 1: Genel ÇimentolarBileşim, Özellikler ve Uygunluk Kriterleri, Türk Standartları Enstitüsü, Ankara, 2012.

[20] ASTM C618, Coal Fly Ash and Raw or Calcined Natural Pozzolan for Use in Concrete, Annual Book of ASTM Standarts, 2012.

[21] TS EN 934-2+A1, Kimyasal katkılar - Beton, harç ve şerbet için - Bölüm 2: Beton kimyasal katkıları, Türk Standartları Enstitüsü, Ankara, 2013.

[22] TS EN 1008, Beton karma suyu- Numune alma, deneyler ve beton endüstrisindeki işlemlerden geri kazanılan su dahil, suyun, beton karma suyu olarak uygunluğunun tayini kuralları, Türk Standartları Enstitüsü, Ankara, 2003.

[23] TS EN 12390-7, Beton - Sertleşmiş beton deneyleri Bölüm 7: Sertleşmiş betonun yoğunluğunun tayini, Türk Standartları Enstitüsü, Ankara, 2019.

[24] Delikurt, B. C., Sevim, U. K., "Sugözü uçucu külünün betonun mekanik ve durabilite özelliklerine etkisi”, Ömer Halisdemir Üniversitesi Mühendislik Bilimleri Dergisi, 4(1), 47-58, 2015.

[25] TS EN 12390-4, Beton - Sertleşmiş beton deneyleri Bölüm 4: Basınç dayanımı - Deney makinelerinin özellikleri, Türk Standartları Enstitüsü, Ankara, 2019.

[26] TS EN 12504-4, Beton deneyleri - Bölüm 4: Ultrasonik atımlı dalga hızının tayini, Türk Standartları Enstitüsü, Ankara, 2004. 
[27] Feldman, R. F., Non-Destructive Testing of Concrete, CBD-187, National Research Council of Canada, Ottawa, Ontario, 1977.

[28] Savva, A. E., "High-strength concrete: mechanical and elastic properties of fly ash and silica fume containing mixtures". In Proc. Int. Conf. on Fly Ash, Silica Fume, Slag, and Natural Pozzolan in Concrete (pp. 125-139), 2001.

[29] Hassan, K. E., Cabrera, J. G., \& Maliehe, R. S., "The effect of mineral admixtures on the properties of highperformance concrete", Cement and concrete composites, 22(4), 267-271, 2000.

[30] Atabey, İ.I., Yurt, Ü., Dündar, B., "Farklı mineral katk1 kullanımının beton dayanım özellikleri üzerine etkisinin araştırılması", Uluslararası Mühendislik Araştırmaları Sempozyumu, Düzce, 2017.

[31] Thomas, M. D. A., Shehata, M. H., Shashiprakash, S. G., Hopkins, D. S., \& Cail, K., "Use of ternary cementitious systems containing silica fume and fly ash in concrete",
Cement and Concrete Research, 29(8), 1207-1214, 1999. [32] Erdem, T. K., \& Kirca, Ö., "Use of binary and ternary blends in high strength concrete", Construction and Building Materials, 22(7), 1477-1483, 2008.

[33] Zhao, S., \& Sun, W., "Effect of silica fume and fly ash on pore structures of blended pastes at low water to binder ratios", Advances in Cement Research, 27(9), 506-514, 2015.

[34] Hanehara, S., Tomosawa, F., Kobayakawa, M., \& Hwang, K., "Effects of water/powder ratio, mixing ratio of fly ash, and curing temperature on pozzolanic reaction of fly ash in cement paste", Cement and Concrete Research, 31(1), 31-39, 2001.

[35] Qing, Y. E., Zenan, Z., Li, S., \& Rongshen, C., “A comparative study on the pozzolanic activity between nano$\mathrm{SiO}_{2}$ and silica füme", Journal of Wuhan University of Technology-Mater. Sci. Ed., 21(3), 153-157, 2006. 